\title{
Las micorrizas: una relación planta-hongo que dura más de 400 millones de años
}

\author{
por \\ Mario Honrubia \\ Departamento de Biología Vegetal (Botánica), Facultad de Biología, Campus de Espinardo \\ Universidad de Murcia, E-30100 Murcia, España
}

\begin{abstract}
Resumen
Honrubia, M. 2009. Las micorrizas: una relación planta-hongo que dura más de 400 millones de años. Anales Jard. Bot. Madrid 66S1: 133-144.

Se define el concepto de micorriza en un sentido amplio, como una simbiosis no necesariamente mutualística, para incluir las relaciones tróficas de hongos micorrícicos con plantas "inferiores" y plantas aclorofílicas. Se realiza una revisión bibliográfica sobre el origen y diversificación de las micorrizas. Se evidencia el carácter pionero de la micorriza arbuscular formada por los Glomeromycota y se resalta su importancia en el proceso de 'terrestrialización'. Se comenta la formación cronológica de los restantes tipos de micorrizas. Se denota la evolución independiente y recurrente de las ectomicorrizas, formadas por Basidiomycota y Ascomycota inicialmente saprófitos, que sugiere una versatilidad en las estrategias nutricionales de estos hongos, como respuesta adaptativa a los cambios ambientales. Similares respuestas debieron ser la causa del origen de las singulares micorrizas ericoides, arbutoides y heliantemoides. Se expone la particular relación trófica entre plantas aclorofílicas como Monotropa o de orquídeas en sus fases hetrotróficas con sus hongos simbiontes. Finalmente, se comenta la reciente evolución de sistemas radicales micotróficamente independientes.
\end{abstract}

Palabras clave: micorrizas, origen, evolución, simbiosis.

\section{Definición y concepto de micorrizas}

El término micorriza, que literalmente significa "hongo-raíz", fue propuesto por Frank (1885), para definir asociaciones simbióticas ("vivir conjuntamente dos o más organismos”), mutualistas, no patógenas, entre raíces de plantas y micelios de hongos, en las que ambos resultan beneficiados.

Actualmente, el concepto de "micorriza" se considera en un sentido más amplio, para dar cabida a aquellas asociaciones simbióticas hongo-planta que no se establecen en raíces, sino en otros órganos de

\begin{abstract}
Honrubia, M. 2009. The Mycorrhizae: a plant-fungus relation that has existed for more than 400 million years. Anales Jard. Bot. Madrid 6651: 133-144 (in Spanish).

The concept of mycorrhiza is considered in a wide sense, as a not necessarily mutualistic symbiosis, covering the trophic relations of mycorrhizal fungi with "inferior" and achlorophyllics plants. A bibliographical review of the origin and diversification of mycorrhizae is made. The pioneering characteristics of the arbuscular mycorrhiza formed by Glomeromycota are discussed, emphasizing its importance during the terrestrialization processes. The chronological appearance of the other types of mycorrhizas is discussed. The independent and recurrent evolution of the ectomycorrhizas formed by Basidiomycota and Ascomycota is discussed; their saprobiont or parasite origin points to the versatile nutritional strategy of these fungi, in adaptative response to environmental changes, as does the origin of the singular ericoid, arbutoid and helianthemoid mycorrhizas. The particular trophic relation between achlorophyllic plants, such as Monotropa and orchids, in their heterotrophic phases, with their "mycorrhizal" fungi is also described. Finally, the recent evolution of the non mycotrophic root systems is commented on.
\end{abstract}

Key words: Mycorrhizae, origin, evolution, symbiosis.

contacto, especializados para el intercambio de nutrientes, como ocurre en orquídeas y otras plantas aclorofílicas y en otras "plantas inferiores", carentes de verdaderas raíces.

El carácter heterótrofo de los hongos les condiciona a obtener su fuente carbonada a partir de otros organismos. Los hongos micorrícicos reciben directamente de las plantas los azúcares que precisan para desarrollarse. A cambio captan del suelo y ceden a sus hospedantes vegetales los nutrientes minerales y el agua que éstos necesitan para crecer. Básicamente, en ello consiste la simbiosis micorrícica. Sin embargo, en el caso 
de las plantas aclorofílicas, el flujo de nutrientes, incluidos los azúcares, es unidireccional, desde el hongo a la planta. Es decir, no hay un mutualismo trófico aparente en sentido estricto, aunque sí una simbiosis ("vivir conjuntamente dos o más organismos”), en la que, al menos, uno de los partícipes resulta beneficiado.

Se reconocen distintos tipos de micorrizas (Honrubia \& al., 2002; Barea \& Honrubia, 2004; Smith \& Read, 2008), en función de las especies fúngicas y vegetales que establecen la asociación y en función de su estrategia nutricional, que posibilita una penetración intracelular, o no, por parte del hongo dentro de las células corticales de la raíz del vegetal. En cualquier caso, en todos los tipos de micorrizas, se establece una interfase de contacto íntimo entre hifas y células vegetales, donde se produce el intercambio de nutrientes de manera bidireccional (los nutrientes minerales son transvasados disueltos en agua desde el hongo a la planta, mientras ésta cede al hongo los azúcares procedentes de su actividad fotosintética) o unidireccional, como hemos indicado para orquídeas y plantas aclorofílicas.

Las micorrizas requieren un desarrollo planta (raíz)hongo (micelio) sincronizado, pues las hifas fúngicas solo colonizan raíces jóvenes, excepto en orquídeas, en las que el hongo puede infectar células del tallo. La planta, en cualquier caso, es quien realmente controla la intensidad de la simbiosis, por el crecimiento de su raíz, pero también por la digestión de la interfase de intercambio, en las endomicorrizas, o por la formación de un singular tipo de raíz (secundaria y de crecimiento limitado), en el caso de las llamadas ectomicorrizas. La raíz constituye en realidad un nicho ecológico donde se desarrolla el hongo, que éste aprovecha (Brundrett, 2002).

Esta disparidad de tipos y estrategias nutricionales son producto de un proceso prolongado y selectivo en cuanto a los grupos fúngicos beneficiados, como veremos a continuación.

\section{Origen de las micorrizas}

Paleozoico, del Ordovícico al Devónico: el triunfo de las micorrizas arbusculares

\section{Contextualización del proceso de terrestrialización}

Numerosos estudios paleobotánicos, morfoanatómicos y filogenéticos basados en técnicas moleculares evidencian que la coevolución mantenida entre hongos micorrícicos y raíces de plantas se remonta al $\mathrm{Pa}$ leozoico, hace más de 400 millones de años (Ma), con el origen de las primeras plantas terrestres. De hecho, los ancestros de los actuales briófitos y helechos ya presentaban asociaciones que recuerdan a las ahora conocidas como micorrizas arbusculares.

Conviene recordar que, en el tiempo en que tuvo lugar la "terrestrialización" (Selosse \& Le Tacon, 1998: colonización de ambientes terrestres por parte de las plantas), la Tierra era muy diferente de como la conocemos ahora, especialmente en términos de paleogeografía de los continentes, paleoclima y, por supuesto, biodiversidad. Además, en ese largo periodo de tiempo, tuvieron lugar fenómenos geológicos (intensa actividad volcánica, derivas continentales) y climáticos (severas glaciaciones, prolongados periodos de profunda sequía, globales y/o locales), que fueron perfilando la biocenosis tal y como la entendemos en la actualidad.

Concretamente en el Ordovícico (500-440 Ma), y finales del Cámbrico (544-500 Ma), periodo en el que se inicia el "asalto" a los ambientes terrestres, los primitivos embriófitos encontraron espacios con climas fríos en las paleolatitudes más meridionales del gran continente Gondwana, opuestos al clima tropical, próximo al ecuador, y los áridos y templados más alejados del mismo, que podrían existir en el resto de paleocontinentes, Laurencia, Siberia y Báltica, e incluso en el propio Gondwana. Las latitudes extremas de alguna de las masas continentales, junto con las elevadas concentraciones de $\mathrm{CO}_{2}$, -estimadas para dicho periodo hasta veinte veces superiores a la actual-, la ausencia de filtros que limitasen la entrada de rayos utravioleta, las fuertes oscilaciones térmicas, etc., permiten especular sobre los fotoperiodos (largos periodos de oscuridad alternados con otros igualmente largos de luz), que debieron sufrir los primeros fotobiontes terrestres, lo cual condicionaría, sin duda, sus estrategias vegetativas y reproductoras. Además, la disponibilidad de agua, nutrientes minerales y materia orgánica era, necesariamente, muy inferior a la de nuestros tiempos. En definitiva, tan exigentes condiciones ambientales respaldan la idea de la importancia de la simbiosis endomicorrícica, como mecanismo de colonización de aquellos paleoambientes progresivamente emergidos.

Por otro lado, parece que la estrategia nutricional de la simbiosis en hongos es incluso anterior a la estructurada por los primitivos Glomeromycota y plantas, según indican Yuan \& al. (2005). De acuerdo con estos autores, los fósiles encontrados en la Formación Doushantou, en Weng'an, al sur de China, presentan hifas estrechamente asociadas con cianobacterias o algas cocoides, a modo de primitivas formas liquénicas, datadas de una antigüedad de entre 551 y $635 \mathrm{Ma}$.

$\mathrm{Al}$ igual que ocurriera con los hongos liquenizados, que debieron surgir al menos varias veces durante la evolución, principalmente entre los Ascomycota, 
según las evidencias moleculares propuestas por Gargas \& al. (1995), la simbiosis micorrícica hubo de aparecer en repetidas ocasiones a lo largo del tiempo y en diferentes lugares de la geografía emergida del Paleozoico. Sin embargo, y a diferencia del mutualismo liquénico, las formas fúngicas que inicialmente se "especializaron" en la simbiosis micorrícica (Glomeromycota) fueron mucho menos diversas, aunque consiguieron estabilizarse morfológicamente y, prácticamente, se han mantenido iguales hasta nuestros días. Otros tipos de micorrizas, como las ectomicorrizas, en las que Ascomycota y Basidiomycota adquieren singular relevancia, surgirán muy tardíamente, en otras situaciones ambientales, como veremos más adelante.

En este sentido, tanto Ascomycota como Basidiomycota han mantenido evolutivamente estrategias nutricionales más versátiles que los Glomeromycota e incluso Zygomycota, puesto que, como sugieren Gargas \& al. (1995), las asociaciones mutualistas liquénicas, principalmente las establecidas por aquéllos, han surgido repetidas veces desde las otras formas nutricionales fúngicas (parásitas y saprobias). Mientras que, por su parte, los hongos ectomicorrícicos, mayoritariamente pertenecientes a Ascomycota y Basidiomyco$t a$, tuvieron su origen en formas saprotróficas (Hibbet $\&$ al., 2000), lo que sugiere, en cualquier caso, que dichas asociaciones fúngicas son inestables y evolutivamente dinámicas.

Una última reflexión, antes de centrarnos en los datos que evidencian el origen de las micorrizas, nos sitúa en el tránsito entre los periodos Ordovícico y Silúrico (445-447 Ma), cuando ocurrió el segundo mayor de los eventos de extinción, en términos de porcentaje de géneros desaparecidos, en la historia de la Tierra. Una profunda glaciación esquilmó buena parte de la biodiversidad marina que se había desarrollado desde el Cámbrico y, sobre todo, a lo largo del Ordovícico. Sin duda, ello influyó en los todavía tímidos intentos de "terrestrialización" de plantas y hongos, que debemos entender que se produjeron de una manera gradual, reiterada y reversible, y espacialmente dispersa.

Asumidas, pues, las exigentes condiciones ambientales que debieron existir en dicho periodo, la coincidencia en tiempo y espacio de micobiontes y fotobiontes posibilitó el establecimiento de la asociación simbiótica para colonizar los nuevos ambientes de la interfase suelo-atmósfera (Selosse \& Le Tacon, 1998). Los micobiontes ya tendrían desarrollada una alta capacidad de prospección tridimensional para la captación de los todavía muy escasos nutrientes disponibles en los sustratos emergentes, mientras que los foto- biontes estarían ya adaptados a la captación de fotones y su conversión en azúcares y preadaptados al intercambio gaseoso (Selosse, 2005). La relación trófica (claramente mutualística en este caso) se establecería a nivel de los órganos de fijación del fotobionte. Su eficiencia resultó tal que ha perdurado más de 400 $\mathrm{Ma}$, sin apenas cambios en el componente fúngico (Glomeromycota) y con enorme diversificación en sus hospedantes fotobiontes, con desarrollo de verdaderas raíces y complejas estucturas aéreas (cormo y sistemas florales), muy evolucionadas.

\section{Interpretación del registro fósil}

Redecker \& al. (2000) estiman en unos $460 \mathrm{Ma}$ la antigüedad de las esporas e hifas fósiles encontradas en el Ordovícico de Wisconsin, que presentan una extraordinaria semejanza con las de los actuales Glomales, Glomeromycota (Schüßler \& al., 2001), y constituyen las primeras evidencias de la existencia de los hongos formadores de las micorrizas arbusculares (Redecker, 2002).

Estos hallazgos constatan, por un lado, la coexistencia de los primitivos Glomales con las primeras plantas, en el inicio de la colonización de ambientes terrestres; mientras que, por otro lado, evidencian que la divergencia del clado Ascomycota/Basidiomycota respecto del de Zygomycota/Glomeromycota ocurrió con anterioridad, lo que coincide con lo propuesto por Berbee \& Taylor (2001), que establecen dicha divergencia en unos $620 \mathrm{Ma}$. Así pues, parece evidente que, previa a la aparición de los Glomales, no se desarrolló la simbiosis micorrícica entre hongos y plantas, pero posteriormente habrán de ser varios clados fúngicos los que la establezcan, con el consiguiente impacto sobre los ecosistemas terrestres (Redecker \& al., 2000).

La importancia de los beneficios, que hoy día conocemos, que conlleva la simbiosis micorrícico-mutualista entre hongos y plantas en relación con la colonización de los adversos ambientes terrestres del $\mathrm{Pa}$ leozoico, fue propuesta por Pirozynski \& Malloch (1975) y ampliamente fundamentada sobre los continuados descubrimientos habidos en los registros fósiles de las rocas sedimentarias de Rbynia Chert, en Escocia (Taylor \& al., 2004), datados en unos $408 \mathrm{Ma}$ (principios del Devónico).

Efectivamente, la presencia de Glomales fósiles encontrados en el Ordovícico (Redecker \& al., 2000) no asegura, sin embargo, el definitivo establecimiento de la simbiosis micorrícico-arbuscular en este periodo. Los primeros datos relativos al desarrollo de estructuras simbióticas en estos paleoecosistemas confirmaron la presencia de arbúsculos, con su tronco basal y ramificaciones bien conservados, en el interior de 
células parenquimáticas de rizomas de Aglaeopbyton (= Rbynia) major del Devónico temprano (Remy \& al., 1994; Taylor \& al., 1995), lo que refuerza la idea de que los hongos micorrícico-arbusculares fueron esenciales para el éxito de las primeras plantas terrestres.

Recientemente, Krings \& al. (2007) han descrito la presencia de hifas aseptadas, hifas portadoras de vesículas y esporas en más del $95 \%$ de los fragmentos estudiados de rizomas de Nothia apbylla (pequeño esporófito, fósil vascular, afín a las Zosterophyllophyta), que recuerdan extraordinariamente a estas mismas estructuras formadas por los hongos endomicorrícicos actuales. La ausencia de arbúsculos, en este caso, no contradice el posible carácter mutualista de los hongos responsables de tales estructuras, ya que tenemos ejemplos actuales similares, en pteridófitos como Psilotum nudum (Duckett \& Ligrone, 2005) y hepáticas como Marchantia (Russell \& Bulman, 2005). Otra diferencia encontrada en los endófitos de Notbia respecto de los Glomales actuales es que tampoco llegan a formar "coils" (enrollamientos típicos del hongo) intracelulares, como ocurre en la mayor parte de los hongos micorrícicos de plantas sin flores. Ello podría ser debido a que los Glomeromycota del Devónico, o incluso anteriores del Silúrico, no fueran exactamente iguales a los actuales, como argumentan Berbee \& Taylor (2007). Hay que entender, efectivamente, que la diversidad no sólo de Glomeromycota, sino de Ascomycota, Basidiomycota, y en general de todos los organismos vivientes en el Paleozoico, sería necesariamente distinta, y probablemente menor, de la existente en nuestros días. Además, resulta obvio recordar que los registros fósiles representan una visión limitada de la biodiversidad de una época concreta, ya que su registro es siempre parcial y localizado geográficamente.

Otra incógnita que plantean los hongos encontrados en los fósiles del Devónico de Rbynia es relativa a la forma de dispersión de las esporas intracelulares, que además están asociadas a hifas (Berbee \& Taylor, 2007). Sin duda, cualquier especulación podría advertirse al respecto. Ahora bien, no podemos obviar las similitudes existentes respecto de los actuales Glomeromycota, cuyas esporas, aunque nunca intracelulares, sí pueden formarse de manera intrarradical, como ocurre en Glomus intrarradices. Por otro lado, esta especie, en asociación con palmeras del género Phoenix, llega incluso a formar estructuras pseudoestromáticas, junto con el tejido radical (Dreyer \& al., en preparación), de difícil interpretación en el contexto del ciclo reproductivo del hongo.

\section{Divergencia cronológica entre el registro fósil y el "reloj molecular"}

Si bien el registro fósil establece la aparición de las primeras plantas terrestres en unos 480-460 Ma de antigüedad, estimaciones basadas en análisis moleculares de secuenciación en proteómica sugieren una mucho más temprana terrestrialización (Heckman \& al., 2001). Estos autores consideran que la colonización habría tenido lugar hace unos $600 \mathrm{Ma}$ y que tanto algas verdes como hongos "superiores" habrían aparecido en la Tierra hace más de $900 \mathrm{Ma}$, remontándonos así hasta el Proterozoico del Precámbrico.

Este conflicto cronológico, surgido entre la escala de tiempo geológico y evolutivo basada en el registro fósil y la basada en el "reloj molecular", obedece a que el primero es, sin duda, incompleto y de difícil interpretación, mientras que el segundo está basado en asumir cambios lineares en el tiempo en secuencias de ADN o proteínas muy concretas. En todo caso, ambos resultan todavía grandemente limitados.

Es evidente, pues, que son necesarios más estudios, que introduzcan datos fósiles y moleculares para alcanzar una correcta aproximación al devenir evolutivo en tiempos de la terrestrialización. En este sentido, Berbee \& Taylor (2007), basados también en técnicas moleculares de alineamiento de aminoácidos en genes que codifican proteínas y en la posición de nucleótidos del ADN-ribosómico y asumiendo las evidencias fósiles de presencia de organismos terrestres en el Devónico, estiman que el clado de los Glomeromycota se originó al menos hace $460 \mathrm{Ma}$, y en consecuencia la terrestrialización no pudo ser muy anterior. Similares resultados ya fueron concluidos por Simon \& al. (1993), mediante secuenciación de genes del ADNribosómico en doce especies de hongos micorrícicoarbusculares, estimando el origen de los Glomeromycota y su diversificación en las tres familias actualmente reconocidas (Glomáceas, Acaulosporáceas y Gigasporáceas) entre los 353 y $462 \mathrm{Ma}$ de antigüedad.

Parece existir, por consiguiente, unanimidad en considerar: a) la existencia de los Glomeromycota desde al menos el Ordovícico (Redecker \& al., 2000), como precursores de los actuales hongos responsables de la micorriza arbuscular; b) que tales estructuras endotróficas se remontan al Devónico temprano (Taylor \& al., 2004); c) que ya entonces las primitivas micorrizas arbusculares deberían ser funcionales, a tenor de las evidencias anatómico-estructurales de la infección, con células vegetales presentando paredes típicamente engrosadas y pigmentadas y con material granular cubriendo las hifas infectivas (Berbee \& Taylor, 2007), y finalmente d) que la endosimbiosis micorrícica hongo vs. planta fue transcendental (Pyro- 
zinski \& Malloch, 1975) en el proceso de terrestrialización.

\section{Evidencias actuales sobre el origen de las micorrizas arbusculares}

En una reciente, y muy completa, revisión sobre la distribución filogenética y evolución de las micorrizas en las plantas terrestres, Wang \& Qiu (2006) confirman que el 80 y $92 \%$, respectivamente de las especies y familias de plantas testadas, son micorrícicas, y que son precisamente las micorrizas arbusculares las predominantes, estando además presentes entre las plantas más primitivas, como hepáticas, pteridófitos y las gimnospermas más antiguas. Concluyen igualmente que las ectomicorrizas se desarrollaron en evolución paralela, repetidas veces, más tardíamente y de forma independiente de las micorrizas arbusculares. Esta hipótesis es respaldada por Brundrett $(2002,2008)$, que estudia la evolución de raíces y micorrizas de plantas terrestres.

Numerosos artículos (Wang \& Qiu, 2006) evidencian que los actuales briófitos, hepáticas y pteridófitos (Read \& al., 2000) presentan, en sus rizoides y raíces respectivamente, estructuras celulares funcional y morfológicamente similares a las micorrizas arbusculares formadas por los Glomeromycota en raíces de plantas "superiores". Efectivamente, a pesar de la ausencia de verdaderas raíces en los briófitos, incluidas las hepáticas, las asociaciones de sus talos con estos hongos son consideradas como micorrizas en sentido amplio (Brundrett, 2008) o como asociaciones antecesoras de las verdaderas micorrizas (Nebel \& al., 2004; Kottke \& Nebel, 2005). Recientemente, Ligrone \& al. (2007) estudian las asociaciones de Haplomitrium, Conocephalum, Fossombronia y Pellia con Glomus, mientras que Monoclea aparece relacionada con Acaulospora; sugieren un origen antiguo de los Glomeromycota estudiados, aunque estiman la presencia de estos hongos (principalmente los Glomus, que forman micorrizas arbusculares en plantas "superiores") en táxones de hepáticas tan separados, más fácilmente explicable considerando un cambio de hospedante desde los traqueófitos hacia las hepáticas. Por su parte, Duckett \& al. (2006) defienden la temprana evolución de la simbiosis de los Glomeromycota, al estudiar la colonización inter e intracelular de estos hongos en talos de Treubia. En cualquier caso, la realidad confirma la formación de micorrizas, en su concepto amplio, entre los Glomeromycota con algunas hepáticas actualmente existentes.

No solamente han sido descritas asociaciones simbióticas de hepáticas con Glomeromycota, sino también con otros grupos fúngicos, como Ascomycota y Basidiomycota (Read \& al., 2000; Wang \& Qiu, 2006).
Resultan especialmente interesantes los datos aportados por Pressel \& al. (2008), que confirman la presencia de Rbizoscyphus (Hymenoscyphus) ericae en los rizoides de Pachyschistochila (Schistochilaceae, Jungermanniidae). Este ascomiceto, cuya capacidad de formar micorrizas con otras hepáticas ya había sido constatada por Read \& al. (2000), es la principal especie responsabe de la "micorriza ericoide", típica de los géneros Erica, Calluna y Vaccinum, entre otras ericáceas. Ello sugiere que su capacidad como hongo micorrícico con hepáticas podría haber precedido al establecimiento de su mutualismo con sus actuales hospedantes naturales, teniendo en cuenta que el origen de las Schistochilaceae se produjo en el Triásico (Pressel \& al., 2008), muy anterior a la aparición de las Ericas, como veremos más adelante. También nos alerta de la versatilidad nutricional de estos hongos, con potencialidad asociativa con grupos vegetales muy dispersos.

La asociación entre hepáticas foliosas con algunos Basidiomycota ha sido igualmente constatada. Read \& al. (2000) comentan la presencia de doliporos en estudios ultraestructurales de los gametófitos subterráneos aclorófilos de Cryptothallus y sus aliados fotosintéticos Aneura. Aislamientos de estos hongos mostraron su capacidad para establecer ectomicorrizas con Betula, lo que evidencia su potencialidad en interconectar los sistemas radicales del abedul con el gametófito aclorofílico de la hepática (Read \& al., 2000).

Los musgos han sido objeto de un reciente estudio en el que Zhang \& Guo (2007) confirman la presencia de estructuras como esporas en la superficie y vesículas y "coils" (incluidas hifas inter e intracelulares) en tejidos gametofíticos de catorce especies de musgos. También ha sido descrita la micorriza arbuscular entre Glomus claroideum y Anthocerops punctatus (Schüßler, 2000), en condiciones experimentales de cultivo.

Por consiguiente, aunque Ascomycota y Basidiomycota presenten la potencialidad y pudieran haber establecido esporádicas asociaciones simbióticas con las primeras plantas terrestres, parece evidente que quienes mejor debieron interpretar el concepto de mutualismo con los rizoides u otros tejidos gametofíticos o con las incipientes raíces de los esporófitos de pteridófitos, en el inicio de la colonización terrestre, fueron sin duda los ancestros de los actuales Glomeromycota.

\section{De finales del Paleozoico a mediados del Mesozoico: confirmación y preponderancia de las micorrizas arbusculares}

En este largo periodo de tiempo, que abarca unos $214 \mathrm{Ma}$, incluiríamos los periodos Carbonífero (360$286 \mathrm{Ma}$ ) y Pérmico (286-245 Ma) del Paleozoico y los 
periodos Triásico (245-208 Ma) y Jurásico (208-146 $\mathrm{Ma})$ del Mesozoico.

Si el Devónico se considera como el periodo de la terrestrialización (aunque ésta se iniciara con anterioridad, en el Silúrico, el Ordovícico e incluso el Cámbrico), de adaptación a los nuevos espacios emergentes y de excitante expansión de la diversidad de plantas terrestres, el Carbonífero es el periodo de su consolidación y diversificación. Se desarrollan los primeros bosques, de pteridófitos; es el periodo de los licopodios arbóreos, de Lepidodendron, Sigillaria, Paralycopodites y otras formas leñosas que alcanzaban los $60 \mathrm{~m}$ de altura. Pero también es el tiempo de Sellaginella, Equisetum e Isoëtes herbáceas, que han llegado hasta nuestros días.

El Pérmico es inicialmente una continuación del Carbonífero; pero, a mitad del periodo, los grandes pteridófitos irán cediendo espacio frente a las primitivas gimnospermas, ginkgos, cicas y primeras coníferas, entre otras, mejor adaptadas a los cambios climáticos, tanto en su parte aérea como en la radical. Se produce seguidamente una progresiva aridez, aunque el periodo concluirá, por contra, con una pronunciada glaciación. El tránsito del Pérmico (Paleozoico) al Triásico (Mesozoico) se caracteriza por el evento de extinción más extensivo jamás habido en la Tierra. Se calcula que, aproximadamente, el $95 \%$ de las especies marinas y el $70 \%$ de las terrestres se extinguieron como consecuencia de dicha glaciación. No obstante, es precisamente en este periodo de transición cuando se constatan los registros de Gigasporaceae y Glomaceae en raíces de cicas del Triásico (Phipps \& Taylor, 1997).

Definitivamente, son las plantas con semillas las que se imponen en el gran Pangea del Triásico, con predominio de las coníferas en el norte, y helechos con semillas y otros grupos de gimnospermas, en el sur. La diversificación de todos ellos persiste durante el Jurásico, donde encontramos, con la separación de Pangea, claros predominios de Cupresáceas, Taxodiáceas y Taxáceas en el hemisferio norte, y Araucariáceas y Podocarpáceas, que ya se habrían originado en el Triásico, en el sur. Las primeras angiospermas surgirán más tarde, en el inicio del Cretácico, y adquirirán un rápido y progresivo protagonismo en el paisaje vegetal hasta el Cretácico superior (84-65 Ma), cuando tiene lugar su dominancia ecológica (Carrión, 2003).

\section{Gametófito vs. esporófito: estado de micorrización}

El exitoso cambio que supuso, en la evolución vegetal, pasar desde las formas gametofíticas haploides de los briófitos a las diploides de los esporófitos de helechos y sus derivadas gimnospermas y el resto de plantas "superiores" no tuvo inicialmente, sin embargo, un paralelismo en el cambio de estrategia micotrófica, a pesar del creciente grado de complejidad adquirido en los sistemas radicales. Es decir, de acuerdo con el registro fósil, los datos filogenéticos y el conocimiento actual sobre presencia de micorrizas arbusculares entre las plantas a lo largo de la evolución, los mecanismos moleculares y celulares que permiten el "acomodo" (reconocimiento, penetración y desarrollo) del hongo (Genre \& al., 2005, 2008) en rizoides y raíces de gametófitos y esporófitos de plantas fueron perfilados por los genomas haploides de los primeros colonizadores (Bonfante \& Genre, 2008), habiéndose mantenido hasta nuestros días en buena parte de la diversidad de plantas actualmente existente.

La presencia de hongos en los talos aclorofílicos de los gametófitos de los primitivos pteridófitos obedece más a una estrategia para asegurar la fuente carbonada por parte del haplonte vegetal que a un proceso de mutualismo con el hongo. Sin embargo, la mayoría de los esporófitos de pteridófitos presentan asociación micorrícico-mutualística con Glomeromycota (Read \& al., 2000; Brundrett, 2002; Wang \& Qiu, 2006). Entre ellos, Lycopodium, Selaginella, Angiopteris, Psilotum, Botrychium, Osmunda, Pteris, Pteridium, Adiantum, Dryopteris, Cheilantes y otros muchos géneros y algunos equisetos forman este tipo de micorrizas en sus hábitats naturales.

Por su parte, todas las primitivas gimnospermas que surgieron en este periodo adoptaron la micorriza arbuscular con Glomeromycota (Wang \& Qiu, 2006; Brundrett, 2008) como estrategia nutricional para colonizar los ambientes cambiantes del Jurásico y Triásico. Así, encontramos que cicas, zamias, encefalartos, welwitcias, ginkgos, efedras, araucarias, agatis, podocarpos, sequoias, metasequoias, enebros, sabinas, tujas, tejos y cipreses, entre otros, establecen micorriza arbuscular. Solamente Wollemia (McGee \& al., 1999), Gnetum (Fassi, 1957; St. John, 1980; Onguene \& Kuyper, 2001; Brundrett, 2002) y todas las pináceas presentan ectomicorrizas, como veremos más adelante.

Finalmente, cabe mencionar que existen claras evidencias de que la micorriza arbuscular es la condición primaria de los sistemas radicales de las angiospermas (Brundrett, 2008), las cuales habrán de incorporarse definitivamente al paisaje vegetal terrestre a lo largo del siguiente periodo y su presencia se incrementará durante el Terciario y Cuaternario. Ello hace del mutualismo micorrícico-arbuscular uno de los más antiguos, abundantes y ecológicamente importantes en la historia y evolución de la Tierra.

La estabilidad en el tiempo y el predominio generalizado entre la diversidad vegetal terrestre, desde sus 
inicios hasta la actualidad, de esta simbiosis ha sido defendida por Kiers \& Van der Heijden (2006). Justifican la persistencia de la cooperación evolutiva en dicha simbiosis, basándose en cuatro conceptos: a) la capacidad adaptativa de su estructura espacial y transmisión pseudovertical; b) la excelencia del intercambio nutricional (carbono/mineral) entre ambos simbióntes; c) la capacidad selectiva de los "socios" más cooperativos en diferentes ambientes, y d) las posibilidades de recompensa o sanción entre los "socios" respectivamente más o menos cooperativos. Estos mecanismos de presión habrían permitido la selección genética de los simbiontes mejor adaptados en cada momento a las cambiantes condiciones ecológicas a lo largo del tiempo.

\section{Diversificación y tipos actuales de micorrizas}

\section{La revolución del Cretácico: el origen de las ectomicorrizas}

El Cretácico (146-65 Ma) es el periodo de expansión y diversificación de las angiospermas. Concretamente, es en el Cretácico Superior, hace tan sólo 84-65 Ma, cuando parecen haber surgido la mayoría de las familias de plantas con flores actuales (Wing \& Boucher, 1998). En este periodo, según Willis \& McElwain (2002) podrían reconocerse hasta seis tipos de biomas globales (Carrión, 2003): bosque polar, bioma templado-cálido, bioma de lluvias de invierno, bioma de desiertos subtropicales, bosque paratropical y bioma de pluviselvas tropicales, que nos permiten comprender la distribución de la vegetación en dicho tiempo.

El fósil más antiguo de angiosperma, Archaefructus liaoningensis, hasta ahora registrado está datado en unos $125 \mathrm{Ma}$ (Sun \& al., 2002; Ji \& al., 2004); sin embargo, el origen del grupo debió de ser anterior, estimándose hacia el Cretácico Inferior (Carrión, 2003), hace unos $140 \mathrm{Ma}$, o incluso anterior. En cualquier caso, su radiación resultó tremendamente rápida, pues en menos de $100 \mathrm{Ma}$ alcanzaron un predominio ecológico generalizado en todo el planeta.

Su éxito, sin duda, se debe a su mejor adaptación a los ambientes terrestres, fundamentalmente por la evolución de los órganos de reproducción y, en general, del cormo en su parte aérea, pero también por la evolución en los sistemas radicales. Brundrett (2002) sugiere la evolución de las raíces a partir de los tallos subterráneos (rizomas) de las primitivas plantas terrestres; plantea una sencilla serie evolutiva, iniciada en las raíces dicotómicas de Selaginella, continuada en raíces con ramificación más organizada y presencia de célula apical de los equisetos, seguida por las raíces de gimnospermas con capas de células indiferenciadas y culminada con las de las angiospermas, que presentan capas celulares y ramificación más organizadas. Esta simplista secuencia ilustra, sin embargo, la progresiva necesidad de incrementar la superficie absortiva de nutrientes del suelo, en paralelo con el aumento de la superficie fotosintética, y la también necesaria tendencia de protección mediante una mayor organización anatómica, con distintas capas celulares bien diferenciadas que protegen el sistema vascular, especializado en el transporte de nutrientes. Las raíces se alargan, se ensanchan, se ramifican con mayor eficacia y se protegen anatómicamente mediante la especialización de las células y, químicamente, con la suberina.

Las angiospermas primitivas mantienen la estrategia trófica de la micorriza arbuscular, como había ocurrido desde el inicio del proceso de terrestrialización con todos los grupos vegetales aparecidos hasta el Cretácico. De hecho, la gran mayoría de las plantas con flores, especialmente las de los trópicos, mantienen dicho mutualismo hoy en día. Las gimnospermas de inicio del periodo son igualmente simbiontes con los Glomeromycota formadores de la micorriza arbuscular. Sin embargo, a lo largo del periodo, en los biomas de climas más exigentes, con mayores oscilaciones climáticas de temperatura y precipitaciones (disponibilidad de agua en suelo), surgen elementos, principalmente arbóreos, de la vegetación (tanto en angiospermas como en gimnospermas), con innovadoras estructuras radicales que les aseguran un éxito adaptativo en tales ecosistemas. Sus sistemas radicales incorporan un novedoso tipo de raíz, secundaria y con crecimiento limitado, que podrá ser colonizada por hongos que se especilizarán en el intercambio de nutrientes con las plantas que los acoge. Son las ectomicorrizas.

Algunos autores (Pirozynski, 1980; Cairney, 2000) estiman que el origen de las ectomicorrizas fue hace unos $200 \mathrm{Ma}$, a mediados del Mesozoico, coincidiendo con la aparición de sus plantas hospedantes. Las pináceas debieron de surgir a finales del Triásico y con toda seguridad en el Jurásico, pero será el Cretácico el periodo de su diversificación (Malloch \& al., 1980). Concretamente, el género Pinus pudo haberse originado entre el Jurásico y el Cretácico Inferior, mientras que otros géneros de las actuales pináceas habrían divergido de sus predecesores hacia el Cretácico $\mathrm{Su}$ perior e incluso en el Terciario, según plantea Nan (1995), quien además establece las posibles rutas de expansión biogeográfica de las actuales pináceas. $\mathrm{Pa}$ ralelamente, las más importantes familias de angiospermas ectomicorrícicas (Fagáceas, Salicáceas, Betuláceas) tuvieron también su origen durante el Cretácico (Malloch \& al., 1980; Ding, 1995; Li, 1996). Mo- 
yersoen (2006) sugiere el origen gondwanalandiano de las Dipterocarpáceas, primitiva familia de angiospermas de distribución tropical, de hace unos $135 \mathrm{Ma}$. Otras familias de plantas con flores, como Rosáceas, Mirtáceas, Fabáceas, Euforbiáceas y Poligonáceas, que mayoritariamente presentan micorrizas arbusculares, tienen representantes con micorrizas ectotróficas (Brundrett, 2002; Pérez-Moreno \& Read, 2004; Wang \& Qiu, 2006); incluso pueden compartir simultáneamente ambos tipos de micorrizas, como ocurre en los actuales Eucalyptus y Populus. También algunas gimnospermas pueden tener esta dual capacidad mutualística, como demostraron Cazares \& Smith (1996) con Tsuga heterophylla y Pseudotsuga menziesii. En definitiva, la aparición de las ectomicorrizas parece obedecer a la necesidad de adaptación a ambientes inhóspitos por parte de diferentes grupos vegetales arbóreos con gran desarrollo aéreo y, por tanto, con elevados requerimientos nutricionales, cuyos sistemas radicales habrían ido evolucionando hacia formas jerárquicamente bien ramificadas.

Los Glomeromycota, especializados en colonizar y establecer el mutualismo arbuscular en partes jóvenes de raíces primarias o secundarias, pero de crecimiento ilimitado, no intervienen en este tipo de nueva simbiosis. Así pues, serán algunos hongos septados, principalmente Basidiomycota, ya presentes en el Cretácico hace más de $130 \mathrm{Ma}$ (Berbee \& Taylor, 1993), cuyo hábito alimenticio era fundamentalmente saprofítico, los que mayoritariamente consoliden el mutualismo ectomicorrícico. En menor medida, algunos grupos de Ascomycota, probablemente de los más recientes (ciertos Pezizales, sobre todo hipogeos), también se incorporan a este tipo de simbiosis. Muchos otros Ascomycota, recordamos, habrían evolucionado paralelamente con la simbiosis liquénica, aunque su versatilidad nutricional ya sería mucho más amplia en este periodo (patógenos de artrópodos, nematófagos, etc.), según demuestran Sung \& al. (2008) y Schmidt \& al. (2007), respectivamente. Por último, sólo de manera testimonial, los Endogonales hipogeos, dentro de los Zygomycota, serán capaces de establecer esta simbiosis ectotrófica.

Así pues, parece que los primeros hongos formadores de ectomicorrizas fueron basidiomicetos saprófitos que se adaptaron a la forma de vida simbiótica; aunque ésta dirección evolutiva (saprófito-micorrícico) ha debido de ser reversible repetidas veces a lo largo del tiempo, como argumentan Hibbett \& al. (2000). La disparidad filogenética de los hospedantes ectotróficos evidencia una aparición repetida de la simbiosis, lo que sugiere la naturaleza oportunista de la respuesta colectiva de ambos simbiontes, planta y hongo, a los cambios ambientales (Wang \& Qiu, 2006).

A pesar de que los primeros fósiles bien conservados de ectomicorrizas (pino $\times$ Rhizopogon o Suillus) están datados de hace sólo unos $50 \mathrm{Ma}$, en el Eoceno Medio (LePage \& al., 1997), el origen de las mismas debió de ocurrir muy anteriormente, en el Cretácico, hace al menos unos $130 \mathrm{Ma}$, y de forma independiente y repetida, como ya hemos mencionado y argumentan Bruns \& Shefferson (2004), con la aparición de las plantas hospedantes. Su desarrollo obedeció probablemente a un proceso adaptativo de colonización de ambientes pobres en nutrientes, edáfica y climáticamente inestables, como hemos indicado anteriormente.

Una variante de las ectomicorrizas son las denominadas "ectendomicorrizas" (E-strain), descritas en pinos y formadas por Ascomycota, como Peziza, Geopyxis, Ascobolus, entre otros géneros próximos (Honrubia \& al., 1997), que a diferencia de las anteriores no forman la típica envoltura del manto alrededor de la raíz afectada y, sin embargo, sus hifas penetran en el interior de las células corticales. Las ectendomicorrizas adquieren especial significado ecológico en situaciones de estrés abiótico, como incendios, prolongados periodos de sequía o inundación, contaminación atmosférica o edáfica, etc. (Torres \& Honrubia, 1997; Díaz \& al., 1996; Honrubia \& Díaz, 1996). Representan una alternativa trófica oportunista para estos grupos fúngicos, frente al debilitamiento de las poblaciones de los hongos ectomicorrícicos, fundamentalmente Basidiomycotina, que habitualmente ocupan el espacio de estas raíces secundarias de crecimiento limitado.

El final del Cretácico y tránsito al Terciario, hace unos $65 \mathrm{Ma}$, se caracteriza por un nuevo episodio de extinción masiva global, conocido como $\mathrm{K} / \mathrm{T}$, que concluyó con la desaparición, entre otros, de los grandes saurios. Al margen de las posibles causas de la extinción, la situación resultante fue el dramático incremento de sustratos disponibles para hongos saprófitos, que vieron favorecida su actividad por el aumento de la humedad y reducción de la insolación, debida al aumento de la contaminación atmosférica (Vajda \& al., 2001; Vajda \& McLoughlin, 2004). Esta dominancia de saprófitos debió de ser pasajera, entendiendo que el restablecimiento de las poblaciones de pteridófitos-gimnospermas y, por supuesto, de las angiospermas debió ser rápido. En estos momentos, las principales estrategias tróficas (micorrizas arbusculares y ectomicorrizas) de las plantas ya estaban desarrolladas. La mayor adaptabilidad de las plantas con flores a las nuevas condiciones les permite su rápido dominio ecológico desde el inicio del Terciario, que ha perdurado hasta nuestros días. 


\section{De los cambios del Terciario al Cuaternario: otros tipos de micorrizas actuales}

El Terciario es el periodo en el que los continentes adquieren su configuración actual; abarca desde los 65 a los 1,8 Ma de antigüedad y es uno de los más cálidos de la historia de la Tierra, especialmente el Eoceno (54-37 Ma).

Esta peculiaridad condicionará nuevos ecosistemas más exigentes, que permiten el desarrollo y expansión de la vegetación esclerófila y xerofítica, frente al declive de los bosques. En este contexto, y habida cuenta de la precedente primacía de hongos saprófitos, consecuencia de la última extinción masiva, se abrirán nuevas alternativas tróficas para los sistemas radicales de los nuevos grupos vegetales formados. Evidentemente, la mayoría de los vegetales mantendrán su condición de micorriza arbuscular, mientras que pináceas, fagáceas, etc., harán lo propio con las ectomicorrizas. Sin embargo, familias como Ericáceas, Cistáceas y Orquidáceas explorarán nuevos mutualismos con Ascomycota y Basidiomycota; mientras que Quenopodiáceas, Ciperáceas y Brasicáceas, principalmente, determinarán estrategias tróficas independientes de las micorrizas.

Las Ericáceas parecen tener su origen en el temprano Terciario (Lewis, 1987). Géneros como Arctostaphylos, Calluna, Erica, Rhododendron, Vaccinum, Epacris y Astroloma (Cairney \& Ashford, 2002; Wang \& Qiu, 2006) entre otros, han desarrollado un particular tipo de micorriza "ericoide" (Smith \& Read, 2008) con Rhizoscyphus (Hymenoscyphus) ericae, cuya capacidad de formar simbiosis con hepáticas (Pressel \& al., 2008) y ectomicorrizas con angiospermas y gimnospermas (Vrälstad \& al., 2002) ha sido demostrada. Recientemente, se ha constatado la asociación micorrícica de distintos géneros y especies de Ericáceas, incluidos los madroños (Arbutus), con Sebacinales (Basidiomycota). Estos hongos presentan una gran amplitud de hospedantes con los que establecen simbiosis diferentes intra o intercelulares (Selosse \& al., 2007). Por su parte, los madroños también han elaborado su particular micorriza, "arbutoide", con otros numerosos Basidiomycota (Massicotte \& al., 1993; Navarro \& al., 2009) que, a su vez, se asocian con diferentes plantas ectomicorrícicas, comunes en sus propios ecosistemas. Finalmente, otros tres géneros aclorofílicos de la familia, Monotropa, Pterospora y Sarcodes, forman su peculiar simbiosis "micorrícica" con Basidiomycota, como Boletus, Rhizopogon y Gautieria, habituales hongos ectomicorrícicos en nuestros bosques (Bidartondo \& Bruns, 2005; Smith \& Read, 2008).
Las orquídeas probablemente se originaron con anterioridad a las ericáceas, durante el Eoceno, hace unos $54 \mathrm{Ma}$ (Arditti, 1977); todas ellas son micoheterotróficas en alguna fase de su ciclo biológico, formando un tipo particular de simbiosis "micorriza orquidioide" con Basidiomycota, como Ceratobasidium (Rhizoctonia), Sebacina, Tulasnella y Russula. Las de orquídeas y otras plantas aclorofílicas hay que entenderlas como simbiosis en sentido amplio y no como un mutualismo propiamente dicho, pues la nutrición carbonada de la planta (además de la mineral) se produce desde el hongo hacia la planta (Brundrett, 2004, 2008). Los mecanismos de atracción de ésta hacia el hongo siguen siendo una interrogante (Smith \& Read, 2008), lo que evidencia la necesidad de profundizar en el conocimiento de esta singular simbiosis.

Las Cistáceas son una pequeña familia de plantas (unos 175 táxones; Mabberly, 1997), de distribución mayoritariamente holártica, muchos de cuyos miembros tienen un papel importante en la vegetación xérica mediterránea del "Viejo Mundo" (Ellul \& al., 2002). Los registros polínicos más antiguos de las Cistáceas están datados en el Mioceno Inferior (Konzalova, 1967), aunque estos datos deben ser tomados con cautela, como indican Guzmán \& Vargas (2005), quienes postulan la divergencia del género Cistus en unos 8-7 Ma. En cualquier caso, junto a las Ericáceas, es una de las familias más importantes en el mantenimiento de nuestros ecosistemas mediterráneos actuales. La versatilidad nutricional es alta, habiéndose constatado numerosos simbiontes fúngicos (Giovannetti \& Fontana, 1982; Comandini \& al., 2006), que a su vez forman ectomicorrizas con muchas otras especies de plantas. Singular atención merece la relación dual entre Helianthemum spp. y Terfezia spp. (micorriza "heliantemoide") que puede variar morfoanatómicamente en función de la disponibilidad de nutrientes (Gutiérrez \& al., 2003; Honrubia \& al., 2007; Morte \& al., 2008).

Finalmente, las Quenopodiáceas, cuyo origen se pudo remontar al Cretácico (Zhu, 1995), y las Crucíferas, mucho más recientes, problablemente originadas en el Cuaternario (Koch \& Mummenhof, 2006), junto con Proteáceas y Ciperáceas, se independizaron de la micotrofía para asegurar su nutrición hidromineral, a través de una decidida apuesta por el desarrollo de raíces finas, no suberizadas, con numerosos pelos radicales. Sobre todo han desarrollado mecanismos para modificar el $\mathrm{pH}$ de la rizosfera, a fin de incrementar la disponibilidad de nutrientes y evitar la colonización de Glomeromycota, acumulando alcaloides y glucosinolatos cianogénicos (Brundrett, 2002). 


\section{Conclusiones}

Las micorrizas arbusculares, formadas por los Glomeromycota, fueron las primeras asociaciones mutualísticas que surgieron entre las primitivas plantas y hongos que emprendieron el proceso de terrestrialización, hace más de $460 \mathrm{Ma}$. Los mecanismos moleculares y celulares que controlan la instalación, presencia y desarrollo del hongo (intra o intercelular) en las raíces de las plantas debieron de quedar definidos ya entonces en los genomas haploides de los pioneros vegetales y se han conservado hasta nuestros días en los esporófitos diploides de las actuales plantas. Los hongos responsables de esta efectiva simbiosis apenas han debido de evolucionar morfoanatómicamente, habida cuenta de las semejanzas existentes entre las estructuras reproductoras y vegetativas encontradas en el registro fósil y de las de los actuales Glomeromycota. Los estudios moleculares en genómica y proteómica de estos hongos, en paralelo con los derivados del registro fósil, ayudan a comprender mejor el complejo y dificultoso proceso de terrestrialización.

Evolutivamente, las ectomicorrizas se originaron de manera independiente de las arbusculares. Probablemente surgieron repetidas veces, en tiempo y espacio, como alternativa adaptativa de diversos grupos vegetales arbóreos a nuevas exigencias ecológicas. En tales ambientes, presumiblemente con predominio de Basidiomycota (aunque también con Ascomycota) adaptados a hábitos saprofíticos pero capacitados de elevada versatilidad trófica, dichas plantas diseñaron un novedoso tipo de raíz (secundaria y de crecimiento limitado) que serviría de base estructural para el desarrollo de la nueva simbiosis mutualista. Una variante de ésta, con especialización de algunos Ascomycota, constituyen las denominadas ectendomicorrizas tipo E-strain.

Después del último episodio de extinción masiva, en el tránsito del Cretácico al Terciario $(\mathrm{K} / \mathrm{T})$, coincidiendo con la diversificación y expansión definitiva de las plantas con flores, algunas de sus familias desarrollan particulares mutualismos con hongos previamente especializados en otros tipos de simbiosis. Son los casos de las micorrizas ericoides de ericas, gayubas, arándanos, con Ascomycota; las micorrizas arbutoides de madroños, con Basidiomycota; las ectomicorrizas de jaras y las micorrizas heliantemoides de jarillas, con Asco y Basidiomycota indistintamente, y por supuesto, las micorrizas, en un sentido amplio, de las plantas aclorofílicas, como Monotropa (micorriza monotropoide), incluso las orquídeas (micorriza orquidioide) establecidas respectivamente también con Ascomycota y Basidiomycota que, a su vez, están asociados tróficamente a otros hospedantes.

Todas estas interacciones nos revelan las profundas interrelaciones existentes en los sistemas edáficos, el dinamismo y la capacidad adaptativa de plantas y hongos, la red nutricional que constituyen los micelios de los hongos micorrícicos y que son la base del funcionamiento de los ecosistemas (Honrubia \& al., 2002; Pérez-Moreno \& Read, 2004).

Ajenas a estas interacciones, han evolucionado recientemente otras familias, como Quenopodiáceas, Ciperáceas y, sobre todo, Brasicáceas, cuyos sistemas radicales se han independizado de la micotrofia generalizada en el resto de las plantas actuales y todas las que las han precedido desde los inicios de la colonización terrestre.

\section{Agradecimientos}

A las Dras. A. Morte, P. Torrente y L.M. Suz, por sus acertados comentarios y sugerencias. Este trabajo ha sido parcialmente financiado por el proyecto n. ${ }^{\circ}$ 03121/PI/05 de la Fundación Séneca de la CARM.

\section{Referencias bibliográficas}

Arditti, J. 1977. Orchid Biology: Reviews and Perspectives I. Cornell University Press, London. Pp 25-46.

Barea, J.M. \& Honrubia, M. 2004. La micorrización dirigida de la planta forestal. In: Vallejo, R. \& al. (ed.), Avances en el estudio de la gestión del monte mediterráneo. CEAM. 84-921259-3-4. Pp: 215-260.

Berbee, M.L. \& Taylor, J.W. 1993. Dating the radiations of the true fungi. Canadian Journal of Botany 71: 1114-1127.

Berbee, M.L. \& Taylor, J.W., 2001. Fungal molecular evolution: genes trees and geologic time. In: McLaughin/McLaughin/Lemke (eds.), The Mycota VII Part B. Systematics and Evolution. Springer-Verlag Berlin Heiidelberg. Pp. 229-245.

Berbee, M.L. \& Taylor, J.W., 2007. Rhynia Chert: a window into a lost world of complex plant-fungus interactions. New Phytologist 174: 475-479.

Bidartondo, M.J. \& Bruns, T. 2005. On the origins of extreme mycorrhizal specificity in the Monotropoideae (Ericaceae): performance trade-offs during seed germination and seedling development. Molecular Ecology 14: 1549-1560.

Bonfante, P \& Genre, A. 2008. Plants and arbuscular mycorrhizal fungi: an evolutionary-developmental perspective. Trends in Plant Science 13: 492-498.

Brundrett, MC. 2002. Coevolution of roots and mycorrhizas of land plants. New Phytologist 154: 275-304.

Brundrett, MC. 2004. Diversity and classification of mycorrhizal associations. Biological Reviews 79: 473-495.

Brundrett MC. 2008. Mycorrhizal Associations: The Web Resource. Date accessed. <mycorrhizas.info〉.

Bruns, T. \& Shefferson, R.P.. 2004. Evolutionary studies of mycorrhizal fungi: milestones and future directions. Canadian Journal of Botany 82: 1122-1132.

Cairney, J.W. 2000. Evolution of mycorrhiza systems. Naturwissenschaften 87: 467- 475 .

Cairney, J.W.G. \& Ashford, A.E. 2002. Biology of mycorrhizal associations of epicrids (Ericaceae). New Phytologist 154: 305-326.

Carrión, JS. 2003. Evolución vegetal. DM. ISBN 84-8425-335-X. $497 \mathrm{pp}$. 
Cazares, E. \& Smith, J.E. 1996. Ocurrence of arbuscular mycorrhizae in Pseudotsuga menziesii and Tsuga heterophylla seedlings grown in Oregon Coastal range soils. Mycorrbiza 6: 65-67.

Comandini, O; Contu, M. \& Rinaldi, A.C. 2006. A overview of Cistus ectomycorrhizal fungi. Mycorrbiza 16: 381-395.

Díaz, G., Barrantes, O., Honrubia, M. \& Gracia, C. 1996. Effect of ozone and sulphur dioxide on mycorrhizae of: Pinus halepensis Miller. Ann. Sci. For. 53: 849-856.

Ding, T-Y. 1995. Origin, divergence and geographical distribution of Salicaceae. Acta Botanica Yunnanica 17: 277-290.

Dreyer, B., Morte, A., López, J.A. \& Honrubia, M. (en preparación). Comparative root morphology and anatomy of four palm species and their relation with the mycorrhizal susceptibility and morphology.

Duckett, J.G. \& Ligrone, R. 2005. A comparative cytological analysis of fungal endophytes in the sporophyte rhizomes and vascularized gametophytes of Tmesipteris and Psilotum. Canadian Journal of Botany 83: 1443-1456.

Duckett, JG., Carafa, A \& Ligrone, R. 2006. A highly differentiated glomeromycotean association with the mucilage-secreting, primitive abtipodean liverwort Treubia (Treubiaceae): clues to the origin of mycorrhizas. American Journal of Botany 93: 797-813.

Ellul, P., Boscaiu, M., Vicente, O., Moreno, V. \& Rosselló, J.A. 2002. Intra- and Interspecific Variation in DNA Content in Cistus (Cistaceae). Annals of Botany 90: 345-351.

Fassi, B. 1957. Ectomycorhizie chez le Gnetum africanum Welw. due a Scleroderma sp., Bulletin de la Société Française de Mycologie 73: 280-285.

Frank B. 1885. Über die auf Wurzeisymbiosen beruhende Ernährung gewisser Bäume durch unterirdische Pilze. Ber Deutsch Bot Ges 3: 128-145.

Gargas, A. DePriest, PT., Grube, M. \& Theler, A. 1995. Multiple origins of lichen symbioses in fungi suggested by SSU rDNA phylogeny. Science 268: 1492-1495.

Genre, A., Chabaud, M., Timmers, T., Bonfante, P. \& Barker, DG. 2005. Arbuscular mycorrhizal fungi elicit a novel intracellular apparatus in Medicago truncatula root epidermal cells before infection. Plant Cell 17: 3489-3499.

Genre, A., Chabaud, M., Faccio, A., Barker, DG. \& Bonfante, P. 2008. Prepenetration apparatus assembly precedes and predicts the colonization patterns of arbuscular mycorrhizal fungi within the root cortex of both Medicago truncatula and Daucus carota. Plant Cell 20: 1407-1420.

Giovannetti, G. \& Fontana, A. 1982. Mycorrhizal synthesis between Cistaceae and Tuberaceae. New Phytol. 92:533-537

Gutiérrez, A., Morte, A. \& Honrubia, M. 2003. Morphological characterization of the mycorrhizae formed by Helianthemum almeriense Pau with Terfezia claveryi Chatin and Picoa lefebvrei (Pat.) Maire. Mycorrbiza 13: 299-307.

Guzmán, B. \& Vargas, P. 2005. Systematics, character evolution, and biogeography of Cistus L. (Cistaceae) based on ITS, trnLtrnF, and matK sequences. Molecular Phylogenetics and Evolution 37: 644-660.

Heckman, D.S., Geiser, D.M., Eidell, B.R., Stauffer, R.L., Kardos, N.L. \& Hedges, S.B. 2001. Molecular evidence for the early colonization of land by fungi and plants. Science 293: 1129-1133.

Hibbett, D.S. Gilbert, L.B. \& Donoghe, M.J. 2000. Evolutionary instability of ectomycorrhizal symbioses in basidiomycetes. $\mathrm{Na}$ ture 407: 506-508.

Honrubia, M. \& Díaz, G. 1996. Effect of simulated acid rain on mycorrhizae of Aleppo pine (Pinus halepensis Miller). Ann. Sci. For. 53: 947-954.

Honrubia, M., Torres, P., Díaz, G., Barreno, E., Morte, A., Sánchez, F., Pérez, P. \& Sánchez-Saorín, J.A. 1997. Efectos de las micorrizas en la restauración de las zonas afectadas por incendios forestales en la Comunidad Valenciana. 345-393 pp. In La Restaura- ción de la Cubierta Vegetal en la Comunidad Valenciana. Ed. Centro de Estudios Ambientales del Mediterráneo CEAM. Generalitat Valenciana. Conselleria deAgricultura y Medio Ambiente. ISBN 84-921259-0-X.

Honrubia, M., Morte, A. \& Díaz, G. 2002. Dinamismo del componente fúngico micorrícico y su incidencia en la regeneración del bosque mediterráneo. In: Charco, J. (coord.), La regeneración natural del bosque mediterráneo en la península Ibérica: evaluación de problemas y propuesta de soluciones. ARBA-MMA (eds.), ISBN 84-922095-5-0. Pp: 87-113.

Honrubia, M., Morte, A. \& Gutiérrez, A. 2007. Las Terfezias. Un cultivo para el desarrollo rural en regiones áridas y semi-áridas. In: Reyna, S. (coord.), Truficultura, Fundamentos y Técnicas, Capítulo 10. Pp. 365-397. Ediciones Mundi-Prensa, Madrid.

Ji, Q., Li, H., Bowe, M., Liu, Y. \& Taylor, D.W. 2004. Early Cretaceous Archaefructus eoflora sp. nov. with Bisexual Flowers from Beipiao, Western Liaoning, China. Acta Geologica Sinica 78: 883-896.

Kiers, E.T. \& Van der Heijden, M.G. 2006. Mutualistic stability in the arbuscular mycorrhizal symbiosis: exploring hypothesis of the evolutionary cooperation. Ecology 87: 1627-1636.

Koch, M.A. \& Mummenhof, K. 2006. Editorial: Evolution and phylogeny of the Brassicaceae. Pl. Syst. Evol. 259: 81-83.

Konzalova, M., 1967. Paleontologicke zprava klokalite. Archiv Geoindustria, Geofond, Prague.

Kottke, I \& Nebel, M. 2005. The evolution of mycorrhiza-like associations in liverworts: an update. New Phytologist 167: 330-334.

Krings M., Taylor. T.N., Hass, H., Kerp., H., Dotzler, N \& Hermsen, E.J. 2007. Fungal endophytes in a 400-million-year-old land plants: infection pathways, spatial distribution, and host responses. New Phytologist 174: 648-657.

LePage, B.A., Currah, RS., Stockey, RA \& Rothwell, GW. 1997. Fossil ectomycorrhizae from the Middle Eocene. American Journal of Botany 84: 410-410.

Lewis, D.H. 1987. Evolutionary aspects of mutualistic associations between fungi and photosynthetic organisms. In: Rayner, A.D.M., Brasier, C.M. \& Moore, D. (eds.), Evolutionary biology of the fungi. Cambridge University Press, Cambridge. Pp. 161-178.

Li, JQ., 1996. The origin and distribution of the family Fagaceae. Acta Phytotaxonomica Sinica 34: 376-396.

Ligrone, R., Carafa, A., Lumini, E., Bianciotto, V., Bonfante P. \& Duckett, J.G. 2007. Glomeromycotean associations in liverworts: a molecular, cellular, and taxonomic analysis. American Journal of Botany 94: 1756-1777.

Mabberley, DJ. 1997. The plant-book. A portable dictionary of the vascular plants. Cambridge: Cambridge University Press.

Malloch, D.W., Pirozynski, K.A. \& Raven, P.H. 1980. Ecological and evolutionary significance of mycorrhizal symbioses in vascular plants (A Review). Proceedings of the National Academy of Sciences USA 77: 2113-2118.

Massicotte, H.B., Melville, L.H., Molina, R., Peterson, R.L. 1993. Structure and histochemistry of mycorrhizar synthesized between Arbutus menziessi (Ericaceae) and two basidiomycetes, Pisolithus tinctorius (Pisolithaceae) and Piloderma bicolor (Corticiaceae). Mycorrbiza 3: 1-11.

McGee, P.A., Bullock, S. \& Summerell, B.A. 1999. Structure of mycorrhizae of Wollemi Pine (Wollemia nobilis) and related Araucariaceae. Australian Journal of Botany 47: 85-95.

Morte, A., Honrubia, M. \& Gutiérrez, A. 2008. Biotechnology and Cultivation of Desert Truffles. In: A. Varma (ed.). Mycorrhiza. Biology, Genetics, Novel Endophytes and Biotechnology. 3rd edition, Chapter 38. Springer-Verlag. Heidelberg, New York. Pp. 467-483. 
Moyersoen B. 2006. Pakaraimaea dipterocarpacea is ectomycorrhizal, indicating an ancient Gondwanaland origin for the ectomycorrhizal habit in Dipterocarpaceae. New Phytologist 172: 753-762.

Nan, L. 1995. Studies on the geographic distribution, origin and dispersal of the family Pinaceae Lindl. Acta Phytotaxonomica Sinica 32: $105-130$.

Navarro, A., Sánchez-Blanco, M.J., Morte, A., Bañon, S. (En prensa). The influence of mycorrhizal infection on water and nutritional status of Arbutus unedo L. treated and not treated with paclobutrazol. Environmental and Experimental Botany.

Nebel, M., Kreier, HP., Preußing, M., Weiß, M. \& Kottke, I. 2004. Symbiotic fungal associations of liverworts are the possible ancestors of mycorrhizae. In: Agerer, R., Piepenbring, M. \& Blanz, P. (eds.), Frontiers in Basidiomycote Mycology. Eching, Germany: IHW-Verlag. Pp. 339-360.

Onguene, N.A. \& Kuyper, T.W. 2001. Mycorrhizal associations in the rain forest of South Cameroon. Forest Ecology Management 140: $277-287$.

Pérez-Moreno, J. \& Read, D. J. 2004. Los hongos ectomicorrícicos, lazos vivientes que conectan y nutren a los árboles en la naturaleza. Interciencia 29: 239-247.

Phipps, C.J. \& Taylor, T.N. 1997. Mixed arbuscular mycorrhizae from the Triassic of Antarctica. Mycologia 88: 707-714.

Pirozynski, K.A. 1980. Interactions between fungi and plants through the ages. Canadian Journal of Botany 59: 1824-1827.

Pirozynski, K.A. \& Malloch, D.W. 1975. The origin of land plnats: a matter of mycotrophism. Biosystems 6: 153-164.

Pressel, S., Ligrone, R., Duckett, J.G. \& Davis, E.C. 2008. A novel ascomycetous endophytic association in the rhizoids of the leaf liverwot family Schistochilaceas (Jungermanniidae, Hepaticopsida). American Journal of Botany 95: 531-541.

Read, D.J., Duckett, J.G., Francis, R., Ligrone, R. \& Russell, A. 2000. Symbiotic fungal association in "lower" plants. Phil. Trans. R. Soc. Lond. B. 355: 815-831.

Redecker, D. 2002. Molecular identification and phylogeny of arbuscular mycorrhizal fungi. Plant and Soil 244: 67-73.

Redecker, D., Kodner, R. \& Graham, L.E. 2000. Glomean Fungi from the Ordovician. Science 289 (5486): 1920-1921.

Remy, W., Taylor, T.N., Hass, H. \& Kerp, H. 1994. Four hundredmillion-year-old vesicular arbuscular mycorrhizae. Proc. Nat. Acad. Sci. (USA) 91: 11841-11843.

Russell, J. \& Bulman, S. 2005. The liverwort Marchantia foliacea forms a specialized symbiosis with arbuscular mycorrhizal fungi in the genus Glomus. New Phytologist 165: 567-579.

Schmidt, A.R., Dörfelt, H. \& Perrichot, V. 2007. Carnivorous fungi from Cretaceous Amber. Science 318: 1743.

Schüßler, A. 2000. Glomus claroideum forms an arbuscular mycorrhiza-like symbiosis with the hornwort Anthoceros punctatus. Mycorrbiza 10: 15-21.

Schüßler, A., Schwarzott, D. \& Walker, C. 2001. A new fungal phylum, the Glomeromycota: phylogeny and evolution. Mycol. Res. 105: 1413-1421

Selosse, MA. 2005. Are liverworts imitating mycorrhizas? New Phytologist 165: 345-349.
Selosse, M.A. \& Le Tacon, F. 1998. The land flora: a phototrophfungus partnership. Tree 13: 15-20.

Selosse, M.A., Setaro, S., Glatard, F., Richard, F., Urcelay, C. \& Weiß, M. 2007. Sebacinales are common mycorrhizal associates of Ericaceae. New Phytologist 174: 864-878.

Simon, L., Bousquet, J., Levesque, R.C. \& Lalonde, M. 1993. Origin and diversification of endomycorrhizal fungi and coincidence with vascular land plants. Nature 363: 67-69.

Smith, S. \& Read, D. 2008. Mycorrhizal Symbiosis. 3er Ed. Academic Press. ISBN 9780123705266.800 pp.

St. John,TV. 1980. A survey of mycorrhizal infection in a Amazonian rain forest. Acta amazonica 10: 527-533.

Sun, G., Ji, Q., Dilcher, D.L., Zheng, S., Nixon, K.C. \& Wang, X. 2002. Archaefructaceae, a New Basal Angiosperm Family. Science 296: 899-904.

Sung, G.H., Poinar, G.O. \& Spatafora, J.W. 2008. The oldest fossil evidence of animal parasitism by fungi supports a Cretaceous diversification of fungal-arthropod symbioses. Molecular phylogenetics and evolution 49: 495-502.

Taylor, T.N., Remy, W., Hass, H. \& Kerp, H. 1995. Fossil arbuscular mycorrhizae from the Early Devonian. Mycologia 87: 560-573.

Taylor, T.N., Klavins S.D., Krings, M., Taylor, E.I., Kerp, H. \& Hass, H. 2004. Fungi from the Rhynia chert: a view from the dark side. Transactions of the Royal Society of Edimburgh-Earth Sciences 94: 457-473.

Torres, P. \& Honrubia, M. 1997. Changes and effects of a natural fire on ectomycorrhizal inoculum potential of soil in a Pinus halepensis forest. For. Ecol. Manag. 96: 189-196

Vajda, V. \& McLoughlin, S. 2004 Fungal Proliferation at the Cretaceous-Tertiary Boundary. Science 303: 1489

Vajda, V., Raine, J.I. \& Hollis, C.J. 2001. Indication of global deforestation at the Cretaceous-Tertiary Boundary by New Zealand fern spike. Science 294: 1700-1702.

Vrälstad, T., Schumacher, T. \& Taylor, A.F.S., 2002. Mycorrhizal synthesis between fungal strains of the Hymenoscyphus aggregate and potential ectomycorrhizal and ericoid hosts. New Phytologist 153: 143-152.

Wang, B. \& Qiu, Y.L. 2006. Phylogenetic distribution and evolution of mycorrhizas in land plants. Mycorrbiza 16: 299-363.

Willis, K.J. \& McElwain, J.C. 2002. The evolution of plants. Oxford Univ. Press.

Wing, S.L. \& Boucher, L.D. 1998. Ecological aspects of the Cretaceous flowering plant radiation. Annual Review of Earth and Planetery Science 26: 379-421.

Yuan, X., Xiao, S. \& Taylor, T.N. 2005. Lichen-like symbiosis 600 Million year ago. Science 308: 1017-1020.

Zhang, Y. \& Guo, LD. 2007. Arbuscular mycorrhizal structure and fungi associated with mosses. Mycorrbiza. 17:319-325.

Zhu, GL. 1995. Origin, differentiation and geographical distribution of Chenopodiaceae. Acta Phytotaxonomica Sinica 34: 486504.

Recibido: 4-III-2009

Aceptado: 17-III-2009 